\title{
Thyme: A natural preservative for seafood
}

\author{
Saman Yousefi \\ Faculty of Veterinary Medicine, Shahrekord Branch, Islamic Azad University, Shahrekord, Iran
}

\begin{abstract}
Nowadays, food preservation for a long time without any change in quality is a global issue. Currently, 25 categories of food additives have been defined. These compounds are used to extend the shelf life of foods by protecting them against microorganisms as well as chemical reactions. Medicinal plants, having proven antimicrobial and antioxidant properties are suitable candidates for this purpose. Among them, thyme with a wide range of bioactive compounds has been extensively studied. This plant belongs to the family Lamiaceae and has a particular situation in traditional medicine. Nowadays, thyme and its derivate present a wide range of functional possibilities in the pharmacy and food industry. This article discusses thyme's application as a food preservative in the seafood industry.
\end{abstract}

\section{Introduction}

In ancient history, medicinal plants were extensively used for different purposes. They were used as spices as well as the therapeutic agents used in wound healing, gastrointestinal disorders, and infectious diseases. ${ }^{1}$ Moreover, several ancient civilizations have used various herbs, including Indians, Egyptians, Romans,

Correspondence: Saman Yousefi, Faculty of Veterinary Medicine, Shahrekord Branch, Islamic Azad University, Rahmatieh, Shahrekord, Iran

Tel.: +983833361045

E-mail: s.yousefi@std.iaushk.ac.ir

Key words: Thyme; seafood; spoilage; bacterial contamination.

Availability of data and materials: All data generated or analyzed during this study are included in this published article.

Ethics approval and consent to participate: Not applicable.

Informed consent: Not applicable.

Received for publication: 23 January 2022.

Revision received: 6 February 2022.

Accepted for publication: 6 February 2022.

This work is licensed under a Creative Commons Attribution NonCommercial 4.0 License (CC BY-NC 4.0).

CCopyright: the Author(s),2022

Licensee PAGEPress, Italy

Infectious Diseases and Herbal Medicine 2022; 3:191

doi:10.4081/idhm.2022.191 and Arabs, due to their culture and traditions. ${ }^{2}$ In consequence, it gave rise to the theocratic viewpoint detected in all ancient civilizations, such as Greece, which was before the advent of the Hippocratic School based on observation and performing experiments. ${ }^{3}$ Thyme, which has been used as a supportive therapeutic agent for thousands of years, belongs to the family Lamiaceae. Scientists have identified over 900 species belonging to the genus Thymus - such as T. serpyllum (wild thyme) and T. vulgaris (common thyme) as the representative species - in several regions, including Europe, Northern Africa, Asia, Southern America, and Australia. The interest in these aromatic medical plants has been increased through the years. ${ }^{4,5}$ In an investigation conducted by De Martino et al., ${ }^{6}$ several other species are noted as the species that are spread widely in the Mediterranean area, such as $T$. satureioides (Morocco), T. willkomii, T. carnosus (Iberian), T. moroderi (Spain), T. grandulosus (Spain and North Africa), T. villosus, T. capitellatus, T. camphoratus (Portugal), T. longicaulis, $T$. poulegioides (Italy), T. lotocephalus, and T. herba-barona. According to their analysis, up to 30 monoterpenes were found in the $T$. vulgaris essential oil, which led to varied chemical compositions of the derivative oils (the species plants) and resulted in the advent of various chemotypes. A study performed by Alu'datt et $a l .{ }^{7}$ illustrates the main active chemicals in thyme oil are hydrocarbon and phenolic compounds, such as borneol, carvacrol, cymol, linalool, thymol, tannin, apigenin, luteolin, saponins, and triterpenic acid. Asllani and Toska ${ }^{8}$ indicated that $T$. vulgaris principally contains $p$-cymene $(7.76 \%-43.75 \%)$, $\gamma$-terpinene $(4.20 \%-27.62 \%)$, thymol (21.38\%-60.15\%), carvacrol (1.15\%-3.04\%), and bcaryophyllene $(1.30 \%-3.07 \%)$. They also reported that orthocymene $(7.76 \%-43.75 \%$ of entire phenolic content) and $\gamma$-terpinene $(4.20 \%-27.62 \%)$ are amongst the main phenolic compounds in thyme oil. On the other hand, the significant hydrocarbon with alcohol group in thyme oil is comprised of linalool $(1.48 \%-3.00 \%)$, borneol $(0.50 \%-1.84 \%)$, terpinen-4-ol $(0.48 \%-$ $1.22 \%)$ and $\alpha$-terpineol $(0.17 \%-0.70 \%)$.

It was indicated that several constituents had antibacterial effects, including thymol, carvacrol, $p$-cymene, and terpinene. For instance, Tohidpour et al. ${ }^{9}$ have proved T. vulgaris responsible for antibacterial effects against 14 clinical isolates of Methicillinresistant Staphylococcus aureus (MRSA), which could be due to the impacts of thymol. Beyond its typical culinary and therapeutic applications, it has been recommended as a preservative in food based on antimicrobial and antioxidant activities.

Food contamination is considered a vital challenge toward the consumers' health. Several bacterial species could result in the spoilage of the food product as well as causing a food-borne disease in humans. In this regard, several pathogenic bacteria have been reported in seafood. ${ }^{10,11}$

A great deal of effort has been devoted to developing methods that can decrease contaminations and increase the shelf life of food products. Adding food additives enhances or adjusts the product's durability or features. This may include its appearance or organoleptic properties; however, it must not modify the current 
structure's nutritional values. It is believed that only limited amounts of the materials are added to food throughout production since they do not contain a considerable nutritional value, either natural or synthetic. Considering the strict regulations to use chemical preservatives, using natural compounds that can increase shelf life has been a matter of interest by researchers. It is proven that some synthetic (chemical) preservatives may have side effects, specifically if antibiotics are being used during production, which results in the development of resistant microorganisms. ${ }^{12}$ Many safer approaches have been announced to prevent food spoilage, such as utilizing herbal, animal, and microbial products. Several studies suggest using ginger, ${ }^{13}$ cumin and mint leaf, ${ }^{14}$ red grape pomace, ${ }^{15}$ thyme, clove, and rosemary extracts, ${ }^{16}$ and oregano or thyme essential oil ${ }^{17}$ as herbal preservatives. Also, as an animal product, chitosan can preserve food products because it contains some antimicrobial and antioxidant components. ${ }^{18}$ They stated that the antimicrobial activity of chitosan is related to the amino and carboxyl groups located on the cell wall of bacteria or fungi. In addition, some bacteria, such as lactic acid bacteria, can produce antimicrobial by-products, including organic acids, which lead to preservative effects. ${ }^{18}$

Different spoilage rates have been identified in foods due to the various constituents. For instance, a higher spoilage rate is detected if more lipids are in the structure of the food. However, the previously mentioned literature review shows that thyme can extend the preservation period, depending on several factors, including the dosage and the conditions. Many reports indicate the effects of thyme on the microbial count and shelf life of seafood. ${ }^{19}$ ${ }^{21}$ In this article, these effects will be discussed.

\section{Antimicrobial effects}

Many species of bacteria have been indicated to be responsible for food spoilage at refrigerator temperature, such as Pseudomonas, Aeromonas, and Flavobacterium genus Altunatmaz et al. ${ }^{22}$ The antimicrobial effects of thyme have been reported several times. ${ }^{23}$ Several compounds have been used against food microbial spoilage. ${ }^{12}$ This property has been attributed to the active ingredients of this plant, such as thymol and carvacrol. Thymol and carvacrol express antimicrobial activity against essential microorganisms such as Escherichia coli O157:H7, Staphylococcus aureus, and Listeria innocua. ${ }^{24}$ Thymol can be extracted from several plants such as Thymus hyemalis, Thymus glandulosus, Thymus zygis, Thymus vulgaris, Origanum dictamnus, Monarda fistulosa, Origanum vulgare, Origanum onites and Origanum compactum. ${ }^{25}$ In vitro and In vivo antimicrobial effects of thyme and other plants containing thymol in the forms of raw material, extract, and essential oil has been frequently proven. ${ }^{26-29}$ Magi et al. ${ }^{30}$ elucidated the effectiveness of utilizing oregano or thyme's essential oils -retaining high contents of carvacrol and thymol - which could particularly inhibit Gram-positive bacteria's growth in comparison to Gram-negative bacteria. Additionally, it is informed of a reduction in campylobacter counts $(0.5 \%)$ after carvacrol and thymol merged. ${ }^{31}$ Some studies indicate TEO's antimicrobial activities, which may be used against several pathogenic organisms, including Aspergillus, Pseudomonas, Streptococci, Salmonella, Bacillus, Listeria and Fusarium. ${ }^{32,33}$ In a recent study, Moumeni Shahraki et al. ${ }^{29}$ reported that $T$. caramanicus was able to prevent in vitro growth of Aeromonas hydrophila. This bacterial species is an important pathogenic agent causing septicemia in many cultured and wild species.

The antimicrobial effects of thyme on rainbow trout fillets during cold storage were studied by Erkan et al. ${ }^{20}$ The total microbial count reached $5.10 \mathrm{cfu} / \mathrm{g}$ in the fillets treated with thyme, according to the results. This value was lower than it in the fillets refrigerated without essential oil. Effects of thyme on fish fillets are presented in Table 1.19,20,34-38

Table 1. Preservative effects of thyme on fish fillet.

\begin{tabular}{|c|c|c|c|}
\hline Medicinal plant & Sample & Effects & Reference \\
\hline 1. Thyme's essential oil 5\% w/w & Mullet & $\begin{array}{l}\text { Decrease microbial count } \\
\text { Increase physicochemical composition } \\
\text { No difference in sensory acceptance }\end{array}$ & [19] \\
\hline 2. Powder $1 \% \mathrm{w} / \mathrm{w}$ & Sea bream & $\begin{array}{l}\text { Increase ice storage } \\
\text { Increase physiochemical composition }\end{array}$ & [34] \\
\hline 3. Thyme's essential oil 1\% w/w & Smoked rainbow trout & $\begin{array}{l}\text { Decrease microbial count } \\
\text { Increase physicochemical composition } \\
\text { Decrease sensory acceptance }\end{array}$ & [20] \\
\hline 4. Thyme's essential oil $1 \% \mathrm{v} / \mathrm{v}$ & Channa argus & $\begin{array}{l}\text { Increase refrigerated storage } \\
\text { Decrease microbial count } \\
\text { Increase physicochemical composition } \\
\text { Decrease sensory acceptance }\end{array}$ & [22] \\
\hline 5. Combined oil nanoemulsion & Rainbow trout & $\begin{array}{l}\text { Increase refrigerated storage } \\
\text { Increase physicochemical composition } \\
\text { Decrease microbial count }\end{array}$ & {$[35]$} \\
\hline 6. Thyme's essential oil & Rainbow trout & $\begin{array}{l}\text { Increase refrigerated storage } \\
\text { Decrease microbial count } \\
\text { Increase physicochemical composition } \\
\text { Increase sensory acceptance }\end{array}$ & {$[36]$} \\
\hline 7. Thyme's essential oil nanoemulsion & Rainbow trout & Decrease microbial count & {$[37]$} \\
\hline 8. Thyme's essential oil with guar gum & Tilapia & $\begin{array}{l}\text { Increase physicochemical composition } \\
\text { Increase sensory acceptance }\end{array}$ & {$[38]$} \\
\hline
\end{tabular}




\section{Antioxidant effects}

Lamiaceae plants are well known to contain a high level of antioxidant constituents. It is stated that based on the antioxidant components found in the thyme extract, scientists identified radical scavenging effects in various in vitro and in vivo conditions. Previously, using an unsaturated lipid system, it was hypothesized that $1 \%$ of oregano impacted the regulation of mackerel oil's oxidation similar to $200 \mathrm{ppm}$ Butylated Hydroxyanisole (BHA). Many studies have indicated the thyme's protective effects on food. ${ }^{36-38}$

According to a previous report, adding thyme powder ( $1 \%$ $\mathrm{w} / \mathrm{w})$ to fish fillets during ice storage resulted in preservative impacts from witnessing exceptional lower levels of TVB-N, TMA-N, free amino acids (NPS), TBA, and LHC. Also, the antioxidant features of various thyme species have been illustrated based on a modified Thiobarbituric Acid (TBA) reactive substances assay (TBARS). ${ }^{39}$ They reported that the species expressing high antioxidant properties were carvacrol-, thymol- or p-cymene-rich oils. According to an experiment reported by Ozogul et al., ${ }^{35}$ a considerable difference was identified when the fillets were treated with thyme compared to the control group. Thyme had also resulted in a $\mathrm{pH}$ decrease in fillets compared to other plant extracts such as rosemary. It shows the antioxidant activity of thyme in preventing ammonia production after a prolonged storage period. Equivalently, in research treating fillets with thyme, it was announced that the TVB-N level of rainbow trout's flesh was less than $20 \mathrm{mg} / \mathrm{kg}$, which was tolerable.

\section{Conclusions}

Different forms of thyme have been investigated as natural antimicrobial agents and antioxidants for food preservation. Based on the literature review, this plant can increase shelf life - which varies from 3-15 days - and decrease the microbial count of fish fillets. The most common dosage of thyme was $1 \%$, and higher dosages may affect the sensory properties of the food, as reported in some studies.

\section{References}

1. Singletary K. Thyme: history, applications, and overview of potential health benefits. Nutrition Today 2016;51:40-9.

2. Aboelsoud NH. Herbal medicine in ancient Egypt. J Med Plants Res 2010;4:082-6.

3. Salehi B, Mishra AP, Shukla I, et al. Thymol, thyme, and other plant sources: Health and potential uses. Phytotherapy Res 2018;32:1688-706.

4. Badi HN, Yazdani D, Ali SM, Nazari F. Effects of spacing and harvesting time on herbage yield and quality/quantity of oil in thyme, Thymus vulgaris L. Industrial crops Products 2004;19:231-6.

5. Nabavi SM, Marchese A, Izadi M, et al. Plants belonging to the genus Thymus as antibacterial agents: From farm to pharmacy. Food Chem 2015;173:339-47.

6. De Martino L, Bruno M, Formisano C, et al. Chemical composition and antimicrobial activity of the essential oils from two species of Thymus growing wild in southern Italy. Molecules 2009;14:4614-24.

7. Alu'datt MH, Rababah T, Alhamad MN, et al. Pharmaceutical, nutraceutical and therapeutic properties of selected wild medicinal plants: Thyme, spearmint, and rosemary. In Therapeutic, probiotic, and unconventional foods. Grumezescu A, Holban AM (eds.) Academic Press, 2018; 275-290.

8. Asllani U, Toska V. Chemical composition of Albanian thyme oil (Thymus vulgaris L.). J Essential Oil Res 2003;15:165-7.

9. Tohidpour A, Sattari M, Omidbaigi R, et al. Antibacterial effect of essential oils from two medicinal plants against Methicillin-resistant Staphylococcus aureus (MRSA). Phytomedicine 2010;17:142-5.

10. Pirali Khairabadi E, Sedigheh Mousavi S, Momtaz H, et al. Prevalence and phylogenetic analysis of Listeria monocytogenes isolated from the fillets of two farmed fish in Shahrekord in 2018. J Food Microbiol 2020;7:81-93.

11. Momeni H, Raissy M, Bashiri M, et al. Fish-borne parasites: A review on the reports from Iran. J Food Microbiol 2020;6:88102.

12. Silva MM, Lidon F. Food preservatives-An overview on applications and side effects. Emirates J Food Agricult 2016;26:366-373.

13. Remya S, Mohan CO, Venkateshwarlu G, et al. Combined effect of $\mathrm{O} 2$ scavenger and antimicrobial film on shelf life of fresh cobia (Rachycentron canadum) fish steaks stored at $2 \mathrm{C}$. Food Control 2017;71:71-8.

14. Raeisi S, Quek SY, Ojagh SM, Alishahi AR. Effects of cumin (C Uminum cyminum L.) seed and wild mint (M Entha longifolia L.) leaf extracts on the shelf life and quality of rainbow trout (O Ncorhynchus mykiss) fillets stored at $4 \mathrm{C} \pm 1$. J Food Safety 2016;36:271-81.

15. Gai F, Ortoffi M, Giancotti V, et al. Effect of red grape pomace extract on the shelf life of refrigerated rainbow trout (Oncorhynchus mykiss) minced muscle. J Aquatic Food Product Technol 2015;24:468-80.

16. Guran HS, Oksuztepe G, Coban OE, Incili GK. Influence of different essential oils on refrigerated fish patties produced from bonito fish (Sarda sarda Bloch, 1793). Czech J Food Sci 2015;33:37-44.

17. Jouki M, Yazdi FT, Mortazavi SA, Koocheki A, Khazaei N. Effect of quince seed mucilage edible films incorporated with oregano or thyme essential oil on shelf life extension of refrigerated rainbow trout fillets. Inte $\mathrm{J}$ Food Microbiol 2014;174:88-97.

18. Baptista RC, Horita CN, Sant'Ana AS. Natural products with preservative properties for enhancing the microbiological safety and extending the shelf-life of seafood: A review. Food Res Int 2020;127:108762.

19. Yasin NM, Abou-Taleb M. Antioxidant and antimicrobial effects of marjoram and thyme in coated refrigerated semi fried mullet fish fillets. World J Dairy Food Sci 2007;2:1-9.

20. Erkan N. The effect of thyme and garlic oil on the preservation of vacuum-packaged hot smoked rainbow trout (Oncorhynchus mykiss). Food Bioprocess Technol 2012;5:1246-54.

21. Yang $\mathrm{F}, \mathrm{Hu} \mathrm{S}, \mathrm{Lu} \mathrm{Y}$, et al. Effects of coatings of polyethyleneimine and thyme essential oil combined with CChitosan on sliced fresh $\mathrm{C}$ hanna argus during refrigerated storage. J Food Process Engin 2015;38:225-33.

22. Altunatmaz SS, Issa G, Aydin A. Detection of airborne psychrotrophic bacteria and fungi in food storage refrigerators. Brazilian J Microbiol 2012;43:1436-43.

23. Nzeako BC, Al-Kharousi ZS, Al-Mahrooqui Z. Antimicrobial activities of clove and thyme extracts. Sultan Qaboos Univ Med J 2006;6:33. 
24. Guarda A, Rubilar JF, Miltz J, Galotto MJ. The antimicrobial activity of microencapsulated thymol and carvacrol. Inte $\mathrm{J}$ Food Microbiol 2011;146:144-50.

25. Figiel A, Szumny A, Gutiérrez-Ortíz A, Carbonell-Barrachina ÁA. Composition of oregano essential oil (Origanum vulgare) as affected by drying method. J Food Engin 2010;98:240-7.

26. Zheng ZL, Tan JY, Liu HY, et al. Evaluation of oregano essential oil (Origanum heracleoticum L.) on growth, antioxidant effect and resistance against Aeromonas hydrophila in channel catfish (Ictalurus punctatus). Aquaculture 2009;292:214-8.

27. Menanteau-Ledouble S, El-Matbouli M. Antigens of Aeromonas salmonicida subsp. salmonicida specifically induced in vivo in Oncorhynchus mykiss. J Fish Dis 2016;39:1015.

28. Raissy, M., Seyed Hasani, A. and Yousefi, S., 2021. Effects of Echinacea on fish growth and health: A review. J Medicinal Herbs 2021;12:13-26.

29. Momeni shahraki M, Sharafati Chaleshtori R, Raissy M, et al. Study of composition and antimicrobial effects of Thymus carmanicus, Zataria multiflora, Rosmarinus Officinalis and Cinnamomum verum essential oils on Aeromonas hydrophila. J Food Microbiol 2021;8:80-90.

30. Magi G, Marini E, Facinelli B. Antimicrobial activity of essential oils and carvacrol, and synergy of carvacrol and erythromycin, against clinical, erythromycin-resistant Group A Streptococci. Front Microbiol 2015;6:165.

31. Arsi K, Donoghue AM, Venkitanarayanan K, et al. the efficacy of the natural plant extracts, thymol and carvacrol against $\mathrm{c}$ ampylobacter colonization in broiler chickens. J Food Safety 2014;34:321-5.

32. Friedman M, Henika PR, Mandrell RE. Bactericidal activities of plant essential oils and some of their isolated constituents against Campylobacter jejuni, Escherichia coli, Listeria monocytogenes, and Salmonella enterica. J Food Protect 2002;65:1545-60.

33. Rassu G, Nieddu M, Bosi P, et al. Encapsulation and modifiedrelease of thymol from oral microparticles as adjuvant or substitute to current medications. Phytomedicine 2014;21:162732.

34. Attouchi M, Sadok S. The effect of powdered thyme sprinkling on quality changes of wild and farmed gilthead sea bream fillets stored in ice. Food Chemistry 2010;119:1527-34.

35. Ozogul Y, Yuvka İ, Ucar Y, et al. Evaluation of effects of nanoemulsion based on herb essential oils (rosemary, laurel, thyme and sage) on sensory, chemical and microbiological quality of rainbow trout (Oncorhynchus mykiss) fillets during ice storage. LWT 2017;75:677-84.

36. Dehghani P, Hosseini SM, Golmakani MT, et al. Shelf-life extension of refrigerated rainbow trout fillets using total Farsi gum-based coatings containing clove and thyme essential oils emulsions. Food Hydrocolloids 2018;77:677-88.

37. Meral R, Ceylan Z, Kose S. Limitation of microbial spoilage of rainbow trout fillets using characterized thyme oil antibacterial nanoemulsions. J Food Safety 2019;39:e12644.

38. Ruelas-Chacon X, Aguilar-González A, de la Luz Reyes-Vega M, Peralta-Rodríguez RD, Corona-Flores J, Rebolloso-Padilla ON, Aguilera-Carbo AF. Bioactive protecting coating of guar gum with thyme oil to extend shelf life of tilapia (Oreoschromis niloticus) fillets. Polymers 2020;12:3019.

39. Dandlen SA, Lima AS, Mendes MD, Miguel MG, Faleiro ML, Sousa MJ, Pedro LG, Barroso JG, Figueiredo AC. Antioxidant activity of six Portuguese thyme species essential oils. Flavour Fragrance J 2010;25:150-5. 